\title{
CORRECTION
}

\section{Correction to: Synthesis, protonation constants and biological activity determination of amino acid-salicylaldehyde-derived Schiff bases}

\author{
Claudia Fattuoni $^{1}\left[\right.$ - Sarah Vascellari ${ }^{2}\left[\right.$ Tiziana Pivetta $^{1}(\mathbb{0}$
}

Published online: 18 February 2020

(c) Springer-Verlag GmbH Austria, part of Springer Nature 2020

\section{Correction to: Amino Acids}

https://doi.org/10.1007/s00726-019-02816-0

Unfortunately in the online published article, the name of compound "L-salicylidenealanine" was published with incorrect spelling in the section "Synthesis of L-salicylideneaniline (1a)". The section should correctly read as "Synthesis of L-salicylidenealanine".

The original article has been corrected.

Publisher's Note Springer Nature remains neutral with regard tojurisdictional claims in published maps and institutional ailiations.

The original article can be found online at https://doi.org/10.1007/ s00726-019-02816-0.

Claudia Fattuoni

cfattuon@unica.it

$\triangle$ Tiziana Pivetta

tpivetta@unica.it

1 Department of Chemical and Geological Sciences,

University of Cagliari, Cittadella Universitaria, Monserrato, 09042 Cagliari, Italy

2 Department of Biomedical Sciences, University of Cagliari, Cittadella Universitaria, Monserrato, 09042 Cagliari, Italy 